\title{
Implementasi Demand Side Management (DSM) Pada Instalasi Pengolahan Air PDAM Mulia Baru
}

\author{
Mulyono $^{1}$ \\ ${ }^{1}$ Universitas Tanjungpura Pontianak \\ ${ }^{1}$ mulyonost7@gmail.com
}

\begin{abstract}
The Mulia Baru Water Treatment Plant (IPA) is one of 6 Water Treatment Plants owned by the Ketapang Regency PDAM that is indicated to use a large amount of electrical energy. From the data obtained during one year (January to December 2017), the average monthly electricity consumption is 128,016,667 $\mathrm{kWh}$ with an average.Drinking Water Production Volume per month of 144,119,833 m3. Therefore the average Specific Energy Consumption (SEC) value for 2017 is 0.89. Through the application of the Peak Clipping and Strategic Concervation DSM program, a decrease in peak load occurs at a time interval between 17:00 and 22:00, in this condition a decrease in load of 0.47 $(\%) . F o r$ greater savings, it is necessary to schedule the operation of large loads at peak load times.
\end{abstract}

Keywords: Electrical Energi, Specifik Energy Consumption, Peak Clipping dan Strategic Conservation

\section{ABSTRAK}

Instalasi Pengolahan Air (IPA) PDAM Mulia Baru merupakan salah satu dari 6 Instalasi Pengolahan Air yang dimiliki PDAM Kabupaten Ketapang yang terindikasi menggunakan energi listrik yang cukup besar. Dari data yang diperoleh selama satu tahun (Januari sampai dengan Desember 2017), pemakaian energi listrik rata-rata perbulan sebesar 128.016,667 kWh dengan Volume Produksi air minum rata-rata per bulan sebesar 144.119,833 m. Dengan demikian ratarata nilai Specifik Energy Consumption (SEC) tahun 2017 sebesar 0,89. Melalui penerapkan program DSM pola Peak Clipping and Strategic Concervation terjadi penurunan beban puncak pada interval waktu pada jam 17.00 hingga jam 22.00, pada kondisi ini terjadi penurunan beban sebesar 0,47 (\%). Untuk penghematan yang lebih besar perlu dilakukan penjadwalan pengoperasian beban-beban besar pada waktu beban puncak.

Kata Kunci: Energi listrik, Specifik Energy Consumption, Peak Clipping dan Strategic Conservation 


\section{Energi dan Kelistrikan: Jurnal Ilmiah}

Vol. 12, No. 1, Januari - Juni 2020, P-ISSN 1979-0783, E-ISSN 2655-5042

https://doi.org/10.33322/energi.v12i1.934

\section{PENDAHULUAN}

Dalam rangka lebih meningkatkan penghematan pemakaian tenaga listrik, perlu dilakukan pemakaian energi listrik secara efesien dan rasional tanpa mengurangi keselamatan, kenyamanan dan produktivitas. Hal tersebut tertuang dalam Peraturan Menteri Energi dan Sumber Daya Mineral Republik Indonesia Nomor 13 Tahun 2012 tentang Penghematan Pemakaian Tenaga Listrik.Penggunaan energi listrik oleh pelanggan masih belum optimal terutama pada waktu beban puncak. Kebutuhan energi listrik pada saat beban puncak akan membawa dampak yang merugikan bagi semua pihak. Oleh karena itu perlu adanya langkah-langka pelaksanaan efesiensi energi secara berkelanjutan di kantor pemerintah, pemerintah daerah, badan usaha milik negara, badan usaha milik daerah dan swasta. Salah satu komponen terbesar dari seluruh biaya yang harus dikeluarkan mayoritas perusahaan daerah air minum (PDAM) di Indonesia adalah biaya listrik atau energi, biaya ini bisa mencapai lebih dari $30 \%$ dari seluruh biaya operasional. Tingginya biaya listrik ini disebabkan oleh pemakaian energi yang tidak sesuai dengan penambahan kapasitas produksi/distribusi air minum, umur peralatan, serta pemakaian energi yang tidak efisien.Instalasi pengolahan air (IPA) PDAM Mulia Baru merupakan salah satu dari 6 (enam) instalasi pengolahan air yang dimiliki PDAM kabupaten Ketapang yakni IPA Mulia Baru, Boster Pump Sukaharja, PDAM IKK Sungai Gayam, Boster Pump Batu Begendang, Boster Pump Banjarsari, dan IKK Benua Kayong. IPA PDAM Mulia Baru yang mulai beroperasi pada tahun 1988 dengan daya PLN sebesar 197 kVA tidak memakai genset sebagai cadangan listrik. IPA PDAM Mulia Baru beralamat jalan Tentemak Kecamatan Delta Pawan Kelurahan Mulia Baru dengan memanfaatkan sumber air baku dari Sungai Pawan. Jenis tarif termasuk tarif Industri dalam golongan I-2/TR dan dikenakan dua jenis biaya yakni biaya beban dan biaya pemakaian, beroperasi selama 24 jam. Konsumsi daya listrik terbesar di IPA PDAM Mulia Baru terletak pada 2 buah pompa intake berkapasitas 70 liter/detik dan 4 buah pompa distribusi berkapasitas 140 liter/detik dengan jumlah pelanggan 4500 sambungan rumah (SR). Menurut data pembayaran tagihan rekening listrik di IPA PDAM Mulia Baru dalam satu tahun (Januari s/d Desember 2017) sebesar 1.536.200 kWh dengan rata- rata pemakaian per bulan sebesar $128.017 \mathrm{kWh}$ dan rata-rata per hari sebesar $1.209 \mathrm{kWh}$, sehingga tagihan listrik yang harus dibayar ke PLN selama satu tahun sebesar Rp. 1.181.597.742. Rata-rata pembayaran per bulan sebesar Rp 98.446.479, dan rata-rata per hari sebesar Rp. 3.282.216. Melihat biaya listrik yang cukup tinggi menjadi beban sangat berat sehingga melemahkan keuangan PDAM kabupaten Ketapang, padahal tujuan dari pada dibentuknya PDAM adalah mampu memberikan kontribusi bagi pendapatan asli daerah (PAD). Berdasarkan uraian di atas, IPA PDAM Mulia Baru salah satu unit instalasi pengolahan air PDAM Kabupaten Ketapang barometer perusahaan milik daerah. Menerapkan Demand Side Management (DSM) menggunakan strategi peak clipping dan konservasi (conservation). Dalam penelitian ini dimaksudkan untuk menghitung nilai Specific Energi Consumption (SEC) berdasarkan pemakaian energi listrik dan volume produksi air bersih, dan juga implementasi ke dalam strategi peak clipping dan konservasi (conservation) di IPA PDAM Mulia Baru, serta untuk merekomendasikan peluang hemat energi berdasarkan data di lapangan, SEDANG manfaat penelitian ini sangat diharapakan Sebagai informasi dan atau referensi bagi lembaga atau perorangan yang ingin melaksanakan program penghematan energi malalui program DSM.Penggunaan energi listrik pada instalasi pengolahan air (IPA) PDAM Mulia Baru Ketapang lebih tertata dan teratur saat beroperasi pada waktu beban puncak pemakaian air dengan menerapkan DSM.Sebagai rekomendasi dalam menentukan kebutuhan energi listrik pada perencanaan instalasi pengolahan air yang akan dibangun nantinya oleh pihak Pemerintah Kabupaten Ketapang. 


\section{METODE PENELITIAN}

\subsection{Pengambilan Data}

Data penelitian terdiri dari data sekunder diperoleh dari data yang telah tersedia dan data primer (pengukuran, survei lapangan maupun wawancara).

a) Data Sekunder

Besarnya penyambungan daya listrik PLN, jenis tarif yang digunakan, Pembayaran rekening listrik PLN bulanan selama satu tahun terakhir.

b) Data Primer

Survei pemakaian energi, wawancara dengan pegawai PDAM Ketapang,

- Analisis data

Analisis dilakukan terhadap seluruh data yang meliputi data sekunder dan data primer.

Analisis data dilakukan melalui pendekatan kuantitatif.

- Analisis Peluang Hemat Energi

Analisis data ditemukan penggunaan energi tidak sesuai standar maka ada peluang dilakukan implementasi program DSM guna memperoleh penghematan energi. Apabila peluang hemat energi telah teridentifikasi, selanjutnya dilakukan analisis peluang hemat energi yaitu dengan cara membandingkan potensi perolehan hemat energi dengan biaya yang harus dikeluarkan untuk pelaksanaan target rencana penghematan energi yang direkomendasikan.

\subsection{Data Penelitian}

Instalasi Pengolahan Air (IPA) PDAM Mulia Baru disuplai dari PLN yang merupakan sumber utama dengan daya terpasang sebesar $197 \mathrm{kVA}$ sesuai tarif industri golongan 1-2/TR dan tidak memiliki genset. Berdasarkan data rekening selama satu tahun (Januari s/d Desember 2017), energi listrik yang digunakan oleh IPA PDAM Mulia Baru yakni 1.536.200 kWh/tahun dan besaran rupiah yang dibayarkan sebesar Rp. 1.181.597.742,-

Tabel 1. Pembayaran Rekening Listrik IPA PDAM Mulia Baru Tahun 2017

\begin{tabular}{|l|l|l|l|r|}
\hline Bulan & Stand meter skrg & Standart Meter Lalu & kWh & Tagihan (Rp) \\
\hline Januari & 2636200 & 2503700 & 132.500 & 102.677 .770 \\
\hline Pebruari & 2765500 & 2636200 & 129.300 & 102.212 .131 \\
\hline Maret & 2879800 & 2765500 & 114.300 & 89.973 .904 \\
\hline April & 3011600 & 2879800 & 131.800 & $103.816,860$ \\
\hline Mei & 3145100 & 3011600 & 133.500 & 105.837 .213 \\
\hline Juni & 3277600 & 3145100 & 132.500 & 102.776 .316 \\
\hline Juli & 3407800 & 3277600 & 130.200 & 102.858 .000 \\
\hline Agustus & 3550900 & 3407800 & 143.100 & 106.498 .159 \\
\hline September & 3685300 & 3550900 & 134.400 & 100.825 .035 \\
\hline Oktober & 3826400 & 3685300 & 141.100 & 104.482 .570 \\
\hline Nopember & 3946000 & 3826400 & 119.600 & 89.237 .634 \\
\hline Desember & 4039900 & 3946000 & 93.900 & 70.402 .150 \\
\hline \multicolumn{2}{|}{ Total } & $\mathbf{1 . 5 3 6 . 2 0 0}$ & $\mathbf{1 . 1 8 1 . 5 9 7 . 7 4 2}$ \\
\hline
\end{tabular}


Energi dan Kelistrikan: Jurnal Ilmiah

Vol. 12, No. 1, Januari - Juni 2020, P-ISSN 1979-0783, E-ISSN 2655-5042

https://doi.org/10.33322/energi.v12i1.934

Tabel 2. Kapasitas dan Volume Produksi IPA PDAM Mulia Baru Tahun 2017

\begin{tabular}{|l|c|c|}
\hline \multicolumn{1}{|c|}{ Bulan } & $\begin{array}{c}\text { Kapasitas Produksi Air Minum } \\
(\mathbf{l} / \mathbf{d t})\end{array}$ & Volume Produksi Air Minum(m $\left.{ }^{\mathbf{3}}\right)$ \\
\hline Januari & 56.595 & 141.067 \\
\hline Pebruari & 56.742 & 129.658 \\
\hline Maret & 56.797 & 150.113 \\
\hline April & 56.708 & 143.909 \\
\hline Mei & 56.339 & 149.342 \\
\hline Juni & 55.906 & 143.617 \\
\hline Juli & 55.867 & 145.893 \\
\hline Agustus & 55.574 & 144.287 \\
\hline September & 55.916 & 144.397 \\
\hline Oktober & 55.876 & 145.360 \\
\hline Nopember & 55.923 & 144.417 \\
\hline Desember & 56.086 & 147.378 \\
\hline Total & $\mathbf{6 7 4 . 3 2 9}$ & $\mathbf{1 . 7 2 9 . 4 3 8}$ \\
\hline
\end{tabular}

Tabel 3. Hasil Produksi IPA PDAM Mulia Baru Tahun 2017

\begin{tabular}{|c|l|c|c|c|c|c|c|}
\hline No & \multicolumn{1}{|c|}{ Bulan } & $\begin{array}{c}\text { Jml } \\
\text { Rek }\end{array}$ & $\begin{array}{c}\text { Vol Air } \\
(\mathbf{m 3})\end{array}$ & $\begin{array}{c}\text { Harga Air } \\
(\mathbf{R p})\end{array}$ & $\begin{array}{c}\text { Biaya } \\
\text { Admin }\end{array}$ & $\begin{array}{c}\text { Pemkaian } \\
\text { Meter (Rp) }\end{array}$ & $\begin{array}{c}\text { Jumlah } \\
(\mathbf{R p})\end{array}$ \\
\hline 1 & Januari & 5.784 & 137.406 & 446.472 .250 & 17.317 .500 & 23.628 .000 & 487.417 .750 \\
\hline 2 & Februari & 5.784 & 137.406 & 446.472 .250 & 17.317 .500 & 23.628 .000 & 487.417 .750 \\
\hline 3 & Maret & 6.083 & 122.070 & 392.389 .250 & 18.213 .000 & 24.825 .000 & 435.427 .250 \\
\hline 4 & April & 6.217 & 149.822 & 532.928 .700 & 18.613 .500 & 25.367 .000 & 576.909 .200 \\
\hline 5 & Mei & 6.336 & 151.008 & 539.453 .100 & 18.968 .500 & 25.845 .500 & 584.268 .100 \\
\hline 6 & Juni & 6.446 & 128.825 & 462.860 .000 & 19.299 .500 & 26.291 .500 & 508.451 .000 \\
\hline 7 & Juli & 6.546 & 150.432 & 533.140 .100 & 19.600 .000 & 26.691 .500 & 579.431 .600 \\
\hline 8 & Agustus & 6.683 & 154.172 & 543.371 .500 & 20.010 .000 & 27.245 .000 & 590.626 .500 \\
\hline 9 & September & 6.791 & 173.879 & 610.211 .600 & 20.334 .000 & 27.680 .000 & 658.225 .600 \\
\hline 10 & Oktober & 6.905 & 141.950 & 505.715 .400 & 20.676 .000 & 28.138 .000 & 554.529 .400 \\
\hline 11 & November & 6.997 & 163.180 & 576.162 .300 & 20.952 .000 & 28.509 .000 & 625.623 .300 \\
\hline 12 & Desember & 7.153 & 149.945 & 534.646 .000 & 21.419 .500 & 29.136 .000 & 585.201 .500 \\
\hline
\end{tabular}

\subsubsection{Kelompok Beban pada IPA PDAM Mulia Baru}

Pada IPA PDAM Mulia Baru beban yang digunakan dapat dikelompokan menjadi:

a) Beban Penerangan

Beban penerangan merupakan beban lampu-lampu yang terpasang, baik yang didalam gedung maupun di luar gedung.

b) Beban lain-lain

Banyak peralatan yang digunakan di IPA PDAM Mulia Baru selama proses produksi maupun peralatan yang mendukung proses produksi tersebut. Peralatan tersebut merupakan beban lain-lain yang digunakan untuk melayani peralatan listrik 1 fasa dan 3 fasa, beban 1 fasa meliputi peralatan listrik dan peralatan elektronik seperti komputer, printer, dispencer dan lainya. Sedangkan untuk 3 fasa seperti mesin bor, mesin las dan lainnya. 
c) Beban Tenaga

Beban tenaga merupakan beban yang memerlukan daya cukup besar, karena pada beban ini menggunakan motor-motor listrik, seperti pompa dan motor.

Data pompa IPA PDAM Mulia Baru meliputi data spesifikasi pompa intake dan data spesifikasi pompa distribusi berturut-turut diperlihatkan pada Tabel 4 dan Tabel 5.

Tabel 4. Data Spesifikasi Pompa Intake

\begin{tabular}{|c|l|l|l|}
\hline No & Spesifikasi Pompa & \multicolumn{1}{|c|}{ Pompa I } & \multicolumn{1}{c|}{ Pompa 2 } \\
\hline 1 & Merk & Ebara 150 x 125 FSHA & Ebara Submersible \\
\hline 2 & Kapasitas (ltr/detik) & 30 & 40 \\
\hline 3 & Head $(\mathrm{m})$ & 20 & 30 \\
\hline 4 & Power & $11 \mathrm{~kW} / 380$ Volt/1450Rpm & $15 \mathrm{Kw} / 380$ Volt/1450Rpm \\
\hline
\end{tabular}

Tabel 5. Data Spesifikasi Pompa Distribusi

\begin{tabular}{|c|c|c|c|c|c|}
\hline No & $\begin{array}{l}\text { Spesifikasi } \\
\text { Pompa }\end{array}$ & Pompa 1 & Pompa 2 & Pompa 3 & Pompa 4 \\
\hline 1 & Merk/Type & $\begin{array}{llll}\text { Ebara } & 80 & \mathrm{x} & 65 \\
\text { FSHA } & & & \\
\end{array}$ & $\begin{array}{l}\text { Ebara } 100 \mathrm{x} \\
\text { 80 FS2JA }\end{array}$ & $\begin{array}{l}\text { Ebara } 100 \mathrm{x} \\
80 \text { FS2JA }\end{array}$ & $\begin{array}{l}\text { Ebara } 100 x \\
\text { 80 FS2JA }\end{array}$ \\
\hline 2 & $\begin{array}{l}\text { Kapasitas } \\
\text { (ltr/dtk) }\end{array}$ & 20 & 40 & 40 & 60 \\
\hline 3 & Head & 10 & 76 & 76 & 76 \\
\hline 4 & Power & $\begin{array}{ll}11 & \mathrm{Kw} / 380 \\
\text { Volt/1450 Rpm }\end{array}$ & $\begin{array}{l}45 \quad \mathrm{Kw} / 380 \\
\text { Volt/50 } \\
\text { HZ/2 Pole } \\
\text { Volt/2950 } \\
\text { Rpm } \\
\end{array}$ & $\begin{array}{l}45 \quad \mathrm{Kw} / 380 \\
\text { Volt/50 } \\
\text { HZ/2 Pole } \\
\text { Volt/2950 } \\
\text { Rpm } \\
\end{array}$ & $\begin{array}{l}45 \mathrm{Kw} / 380 \\
\text { Volt/50 } \\
\mathrm{HZ} / 2 \quad \text { Pole } \\
\text { Volt/2950 } \\
\mathrm{Rpm}\end{array}$ \\
\hline
\end{tabular}

\section{HASIL DAN PEMBAHASAN}

\subsection{Pemakaian Energi Listrik pada IPA PDAM Mulia Baru}

Instalasi Pengolahan Air (IPA) PDAM Mulia Baru disuplay dari PLN digunakan untuk operasional peralatan listrik meliputi beban penerangan, beban stop kontak dan beban tenaga. Data pemakaian energi listrik untuk operasional IPA PDAM Mulia Baru di perlihatkan pada Tabel 6. Total energi listrik yang digunakan per hari sebesar $4137 \mathrm{kWh}$.

Tabel 6. Data Pemakaian Energi untuk Aktifitas IPA PDAM Mulia Baru

\begin{tabular}{|c|l|l|l|l|l|}
\hline No & \multicolumn{1}{|c|}{ Jenis Peralatan } & $\begin{array}{c}\text { Jumlah } \\
\text { (unit) }\end{array}$ & $\begin{array}{c}\text { Daya } \\
\text { (Watt) }\end{array}$ & $\begin{array}{c}\text { Durasi } \\
\text { (jam) }\end{array}$ & $\begin{array}{c}\text { Jumlah Energi } \\
\text { (kWh }\end{array}$ \\
\hline 1 & Kipas angin berkaki & 2 & 134 & 7 & 0,938 \\
\hline 2 & TV & 1 & 322 & 5 & 1.61 \\
\hline 3 & Dispenser & 1 & 356 & 9 & 3.204 \\
\hline 4 & PC & 1 & 294 & 3 & 0.882 \\
\hline 5 & Printer & 1 & 25 & 1 & 0.025 \\
\hline 6 & Lampu Neon CPL & 15 & 540 & 2 & 2.16 \\
\hline 7 & Las Listrik Mini & 1 & 450 & 2 & 0.9 \\
\hline 8 & Mesin Bor & 1 & 320 & 1 & 0.32 \\
\hline 9 & Pompa Intake & 2 & 26000 & 24 & 624 \\
\hline 10 & Pompa Distribusi & 4 & 146000 & 24 & 3.504 \\
\hline
\end{tabular}


Biaya operasional IPA PDAM Mulia Baru meliputi biaya pemakaian energi listrik, biaya administrasi dan biaya pemeliharaan. Gambar 4.2 dan Gambar 4.3 memperlihatkan pembayaran rekening listrik dan penjualan produksi air bersih pada IPA PDAM Mulia Baru tahun 2017.

Pemakaian energi listrik dan volume produksi air minum IPA PDAM Mulia Baru tahun 2017 diperlihatkan pada Gambar 1.

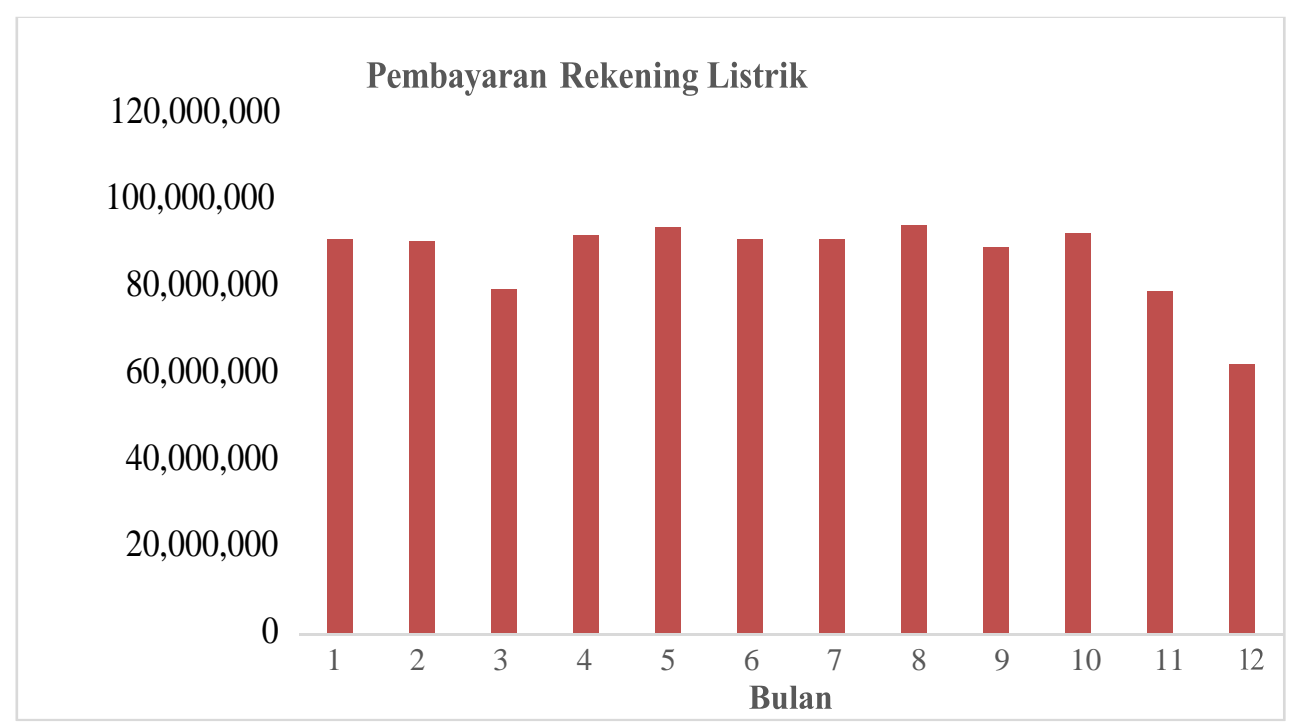

Gambar 1. Pembayaran Rekening Listrik Tahun 2017

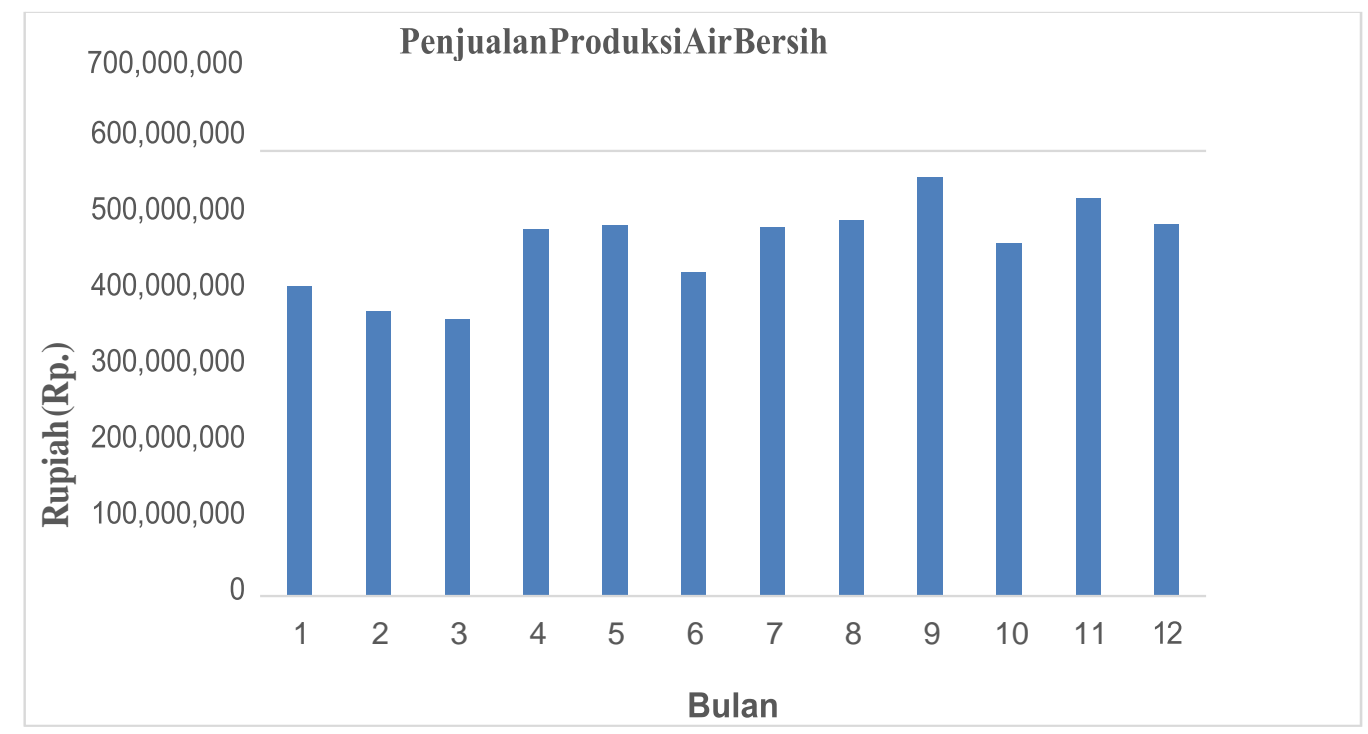

Gambar 2. Penjualan Produksi Air Minum 


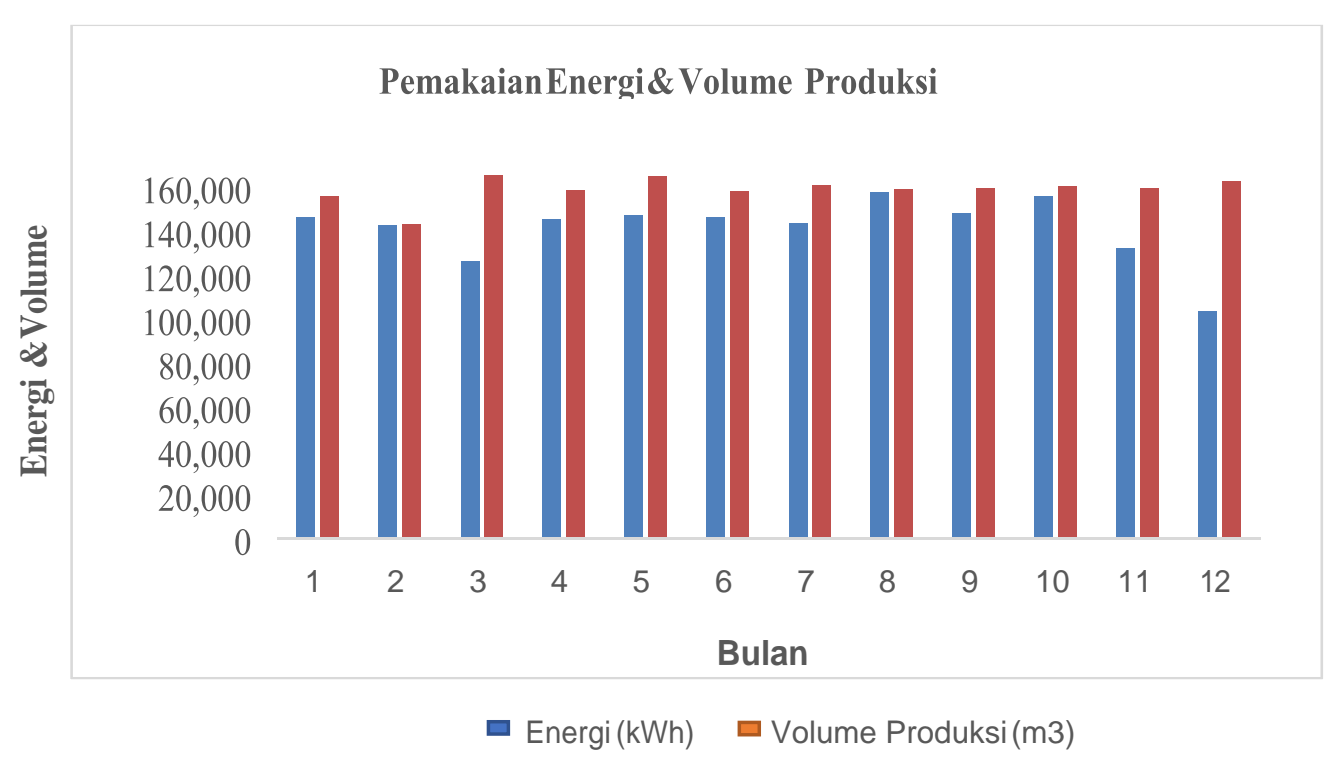

Gambar 3. Pemakaian Energi Listrik dan Volume Produksi Air Minum

Konsumsi energi spesifik (Specific Energy Consumption: SEC) untuk operasional IPA PDAM Mulia Baru tahun 2017 diperlihatkan pada Tabel 7 dan Gambar 4. Dari tabel tersebut terlihat bahwa nilai SEC tertinggi terjadi pada bulan Pebruari 2017 dan terendah pada bulan Desember 2017. Rata-rata nilai SEC tahun 2017 adalah 0.89.

Tabel 7. Nilai Spesifik Energy Consumption

\begin{tabular}{|l|l|l|l|}
\hline Bulan & $\begin{array}{l}\text { Energi } \\
(\mathrm{KWh})\end{array}$ & $\begin{array}{l}\text { Volume Produksi } \\
\left(\mathrm{m}^{2)}\right.\end{array}$ & $\begin{array}{l}\mathrm{SEC} \\
\left(\mathrm{kWh} / \mathrm{m}^{2}\right)\end{array}$ \\
\hline Januari & 132.500 & 141.067 & 0.939 \\
\hline Februarti & 129.300 & 129.658 & 0.997 \\
\hline Maret & 114.300 & 150.113 & 0.761 \\
\hline April & 131.800 & 143.909 & 0.915 \\
\hline Mei & 133.500 & 149.342 & 0.894 \\
\hline Juni & 132.500 & 143.617 & 0.922 \\
\hline Juli & 130.200 & 145.893 & 0.892 \\
\hline Agustus & 143.100 & 144.287 & 0.922 \\
\hline September & 134.100 & 144.397 & 0.931 \\
\hline Oktober & 141.100 & 145.460 & 0.971 \\
\hline November & 119.600 & 144.417 & 0.828 \\
\hline Desember & 93.900 & 147.378 & 0.637 \\
\hline Rata-rata & 128.017 & 144.199 & 0.890 \\
\hline
\end{tabular}




\section{Energi dan Kelistrikan: Jurnal Ilmiah}

Vol. 12, No. 1, Januari - Juni 2020, P-ISSN 1979-0783, E-ISSN 2655-5042

https://doi.org/10.33322/energi.v12i1.934

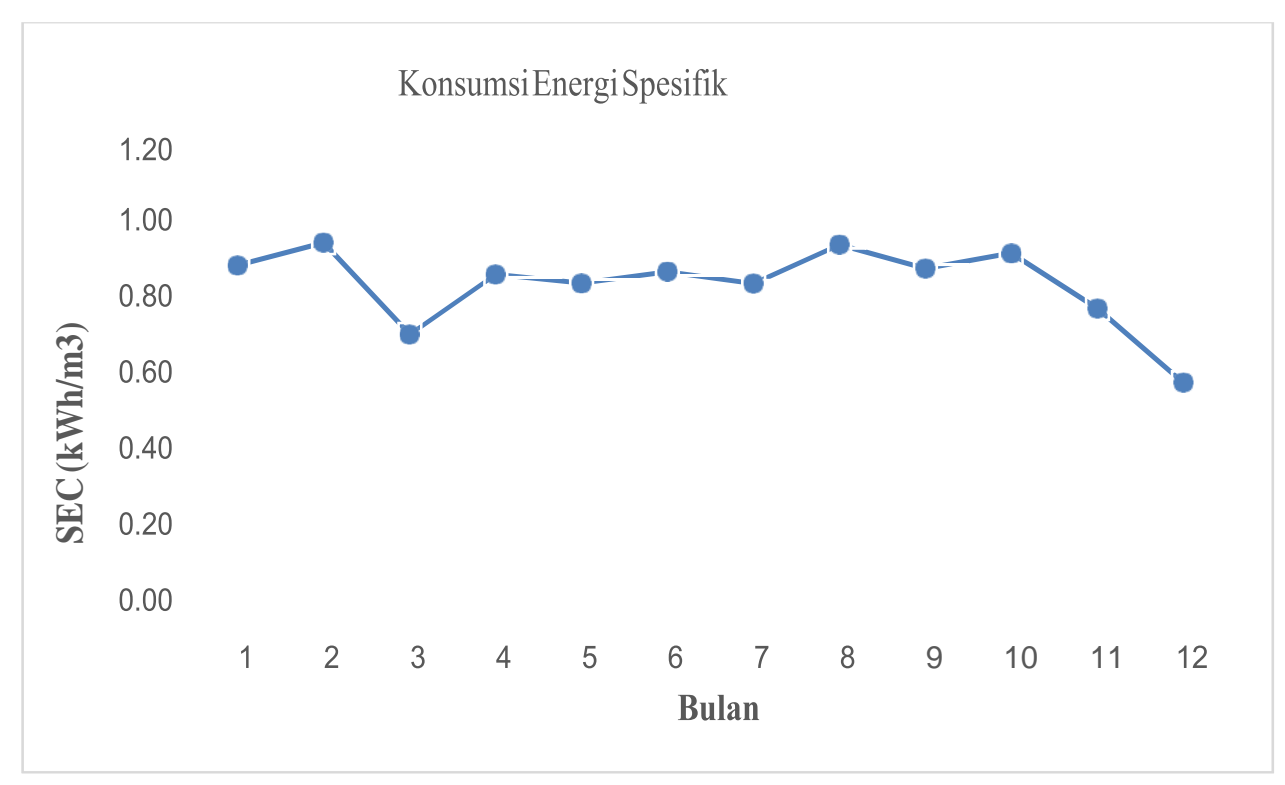

Gambar 4. Specific energy consumption (SEC) tahun 2017

\subsection{Analisis Peluang Hemat Energi}

Peluang penghematan energi dalam tesis ini menggunakan pola peak clipping and Strategic Conservation. Gambar 5 memperlihatkan kondisi beban harian pada IPA PDAM Mulia Baru. Beban puncak terjadi pada interval waktu dari jam 17:00 hingga jam 22:00.

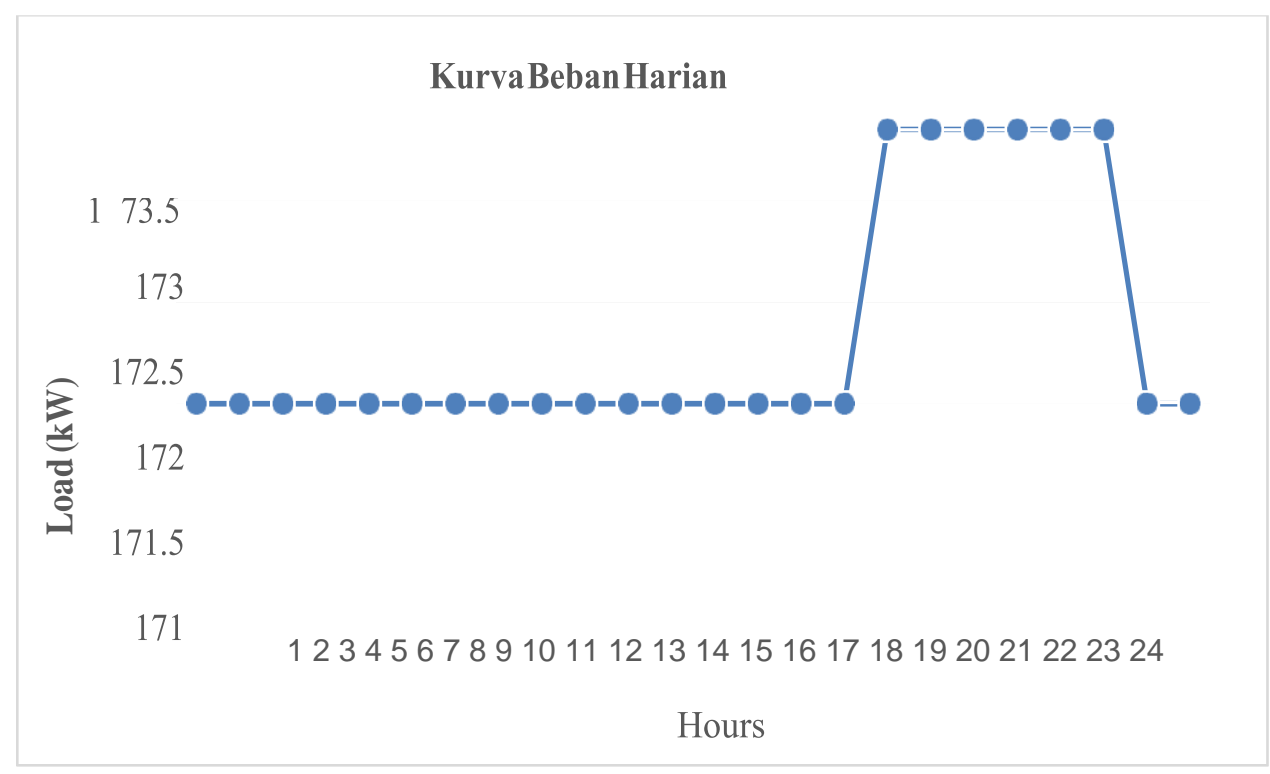

Gambar 5. Kurva Beban Harian IPA PDAM Mulia Baru

Pada bagian ini akan diperlihatkan bagaimana penerapan Demand Side Management (DSM) menggunakan strategi peak clipping (sub. bab 2.5. bagian c) pada beban harian IPA PDAM Mulia Baru seperti diperlihatkan pada Gambar 6. Informasi yang diperoleh dari gambar tersebut memperlihatkan bahwa terjadi penurunan beban puncak pada interval waktu dari jam 17:00 hingga jam 22:00. Pada kondisi ini terjadi penurunan beban sebesar 0,47 (\%). Untuk penghematan yang lebih besar perlu dilakukan penjadwalan pengoperasian beban-beban besar pada interval waktu beban puncak. Strategi konservasi energi dapat dilakukan dengan penggantian peralatan yang lebih 
efisien dalam penggunaan energi listrik, disamping itu dapat dilakukan dengan pengaturan penjadualan peralatan listrik yang digunakan.

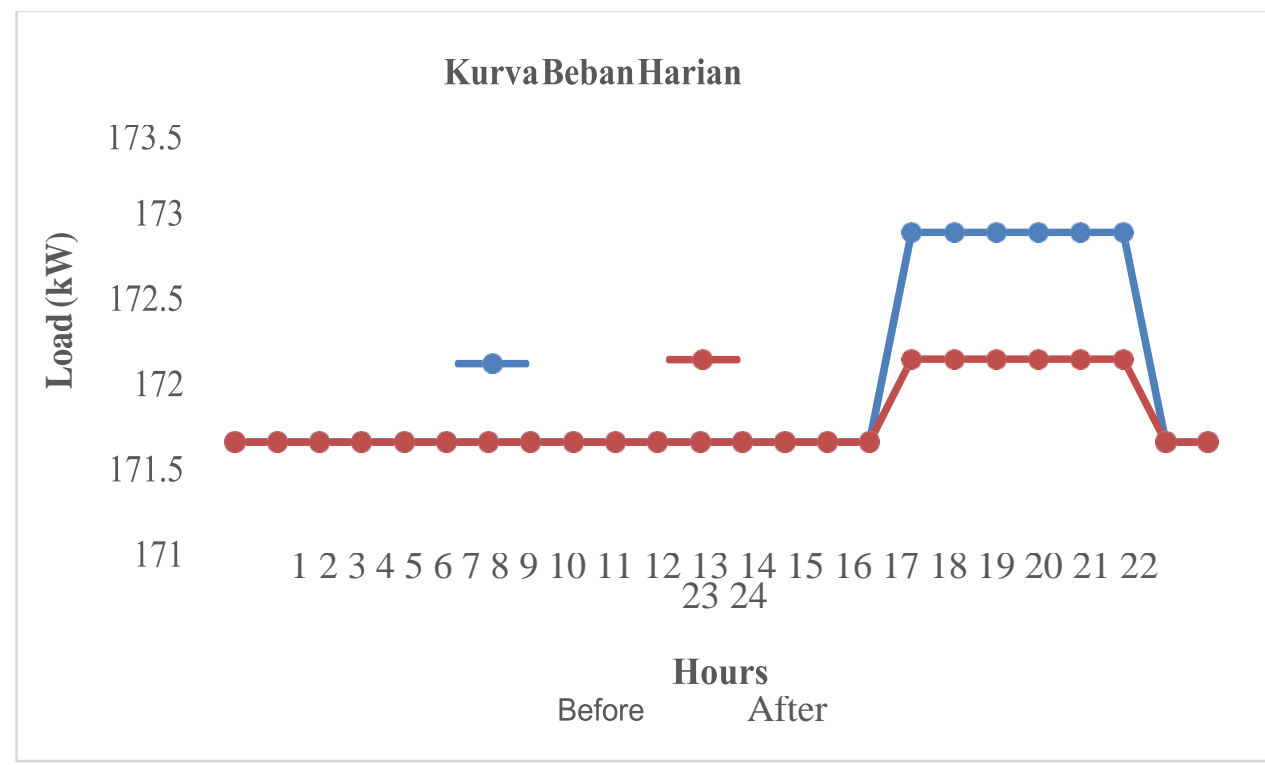

Gambar 6. Kurva Beban Harian IPA PDAM Mulia Baru Setelah Penerapan Strategi Peak Clipping

\subsection{Rekomendasi Peluang Hemat Energi}

Rekomendasi peluang penghematan energi dapat dilakukan sebagai berikut:

a) Manajemen PDAM Mulia Baru melakukan peninjauan kembali (diwaktu beban puncak) pada pengoperasian pompa-pompa baik dibagian intake maupun pada bagian distribusi air ke konsumen agar lebih efisien,

b) Penggunaan SOP (Standar Operasional Prosedur) pada penggunaan mesin atau pompa dan jadwal perawatan peralatan listrik terutama di ruang produksi air bersih,serta penggantian pipa pada jalur distribusi yang dianggap ada kebocoran perlu dilakukan secara berkala,

Apabila rekomendasi dilakukan oleh manajemen PDAM Mulia Baru, maka diperoleh penghematan baik pada sisi pemakaian energi listrik maupun pada bagian produksi air minum (penurunan losses atau tingkat kebocoron).

\section{KESIMPULAN DAN SARAN}

Penelitian yang dilakukan selam ini didapatkansuatu nhasil yang dapat disimpulkan,pola beban pada IPA PDAM Mulia Baru kabupaten Ketapang didominasi oleh beban tenaga (pompapompa) sebesar $99,76 \%$, beban penerangan sebesar $0,05 \%$, dan beban lain-lain sebesar 0,19\%,pemakaian energi listrik pada IPA PDAM Mulia Baru kabupaten Ketapang rata-rata per bulan sebesar 128,017 $\mathrm{kWh}$, sedangkan volume produksi air minum rata-rata per bulan sebesar $144.119,833 \mathrm{~m}^{3}$. Rata-rata nilai SEC tahun 2017 adalah sebesar 0,89 (baik),penerapkan pola beban peak clipping dan strategi konservasi energi, kurva beban harian (peak load) mengalami penurunan atau pergeseran ke arah penghematan sebesar $0,47 \%$ serta adanya peluang penghematan energi dapat dilakukan dengan penjadwalan pemakaian peralatan listrik khususnya beban-beban besar. Disamping itu dapat dilakukan dengan pengendalian beban langsung (direct load control) pada kondisi beban puncak. 


\section{Energi dan Kelistrikan: Jurnal Ilmiah}

Vol. 12, No. 1, Januari - Juni 2020, P-ISSN 1979-0783, E-ISSN 2655-5042

https://doi.org/10.33322/energi.v12i1.934

\section{DAFTAR PUSTAKA}

[1] Undang-undang nomor 30 tahun 2009 tentang Ketenagalistrikan.

[2] Peraturan Menteri Energi dan Sumber Daya Mineral Republik Indonesia nomor 13 tahun 2012 tentang Penghematan Pemakaian Tenaga Listrik.

[3] Direktorat Pengembangan Air Minum, Direktorat Jenderal Cipta Karya, Kementerian Pekerjaan Umum dan Perumahan Rakyat bekerjasama dengan USAID IUWASH dan USAID ICED. Pedoman Pelaksanaan Efisiensi di PDAM di http://www.iuwashplus.or.id.2017.

[4] Selamet Riadi, dkk., Audit Energi untuk Mencapai Peluang Penghematan Energi, Jurnal Teknologi, Vol. 7, No. 1, Januari 2017.

[5] Lukas Santoro, Karnoto, dan Yuningtyastuti, Analisis Pola Beban Listrik Wilayah Jawa Tengah dan DIY menggunakan Strategi Demand Side Management, Jurusan Teknis Elektro, Universitas Diponegoro Semarang, 2014.

[6] Agus Mirza, Implementasi Demand Side Management (DSM) di Fakultas Teknik Universitas Tanjungpura Pontianak, Tesis, Universitas Tanjungpura Pontianak, 2009.

[7] Paracha, Zahir J. and Doulai, Parviz, Load Management-Techniques and Methods in

[8] Electric Power Systems, Energy Conservation and Management, Department Astina Electronic Pte. Ltd, Singapore, 1998.

[9] Budiono Mismail, Rangkaian Listrik: jilid pertama, Penerbit ITB, 1995.

[10] M. Jimi Rizaldi, Pengaturan Pola Penggunaan Energi Menggunakan Load Shifting Demand Side Management (DSM), Tesis, Universitas Tanjungpura Pontianak, 2017.

[11] Peraturan Presiden RI Nomor 8 Tahun 2011 tentang Tarif Tenaga Listrik.

[12] Abdul Kadir, Prof, Ir., Energi, Penerbit Universitas Indonesia, Cetakan ke- 2, Jakarta, 1987.

[13] Best Practices Guidebook, Demand Side Management for Pasific Island Power Utilities, UNDESA/SOPAC-IIEC.

[14] Farla J., Blok K., Schipper L, Energy Efficiency Developments in the Pulp and Paper Industry, Energy Policy, 25, pp. 745-758, 1997. 